\section{Immunocytochemical detection of herpes viruses in oral smears of HIV-infected patients}

Langford A, Kunze R, Schmelzer S, Wolf H, Pohle H-D, Reichart P: Immunocytochemical detection of herpes viruses in oral smears of HIV-infected patients. J Oral Pathol Med 1992; 21: 49-57.

Cytologic smears (CS) were taken from the lateral border of the tongue of HIVseropositive patients (HIV +$)(n=39)$ and of seronegative controls (HIV -) $(n=19)$ and examined by immunocytochemistry (APAAP) and in situ hybridization (ISH) (biotinylated DNA probes) for the presence of viral antigens/DNA of EBV and CMV. While none of the HIV controls showed positive results for EBV antigen, $61 \%$ (APAAP) resp. 79\% (ISH) of oral epithelial cells in the group of HIV + patients were EBV-positive. While all CS taken from areas with the clinical diagnosis of hairy leukoplakia (HL) were EBV positive (APAAP and/ or ISH), the detection of EBV in CS from uninvolved oral mucosa seemed to be associated with the later development of HL. In the group of HIV + patients the detection rate for CMV was about five times (APAAP) resp. three times (ISH) higher than in HIV - persons. This non-invasive technique seems to be a valuable tool to screen for viral antigens/genoms.
A. Langford', R. Kunze ${ }^{2}$, S. Schmelzer ${ }^{1}$, H. Wolf ${ }^{3}$, H.-D. Pohle ${ }^{4}$ and P. Reichart ${ }^{1}$

'Abteilung für zahnärztliche Chirurgiel Oralchirurgie-Nord, Freie Universität, 'Imtox Immunbiologische Forschungs $\mathrm{GmbH}$, Berlin, ${ }^{3}$ Max von Pettenkofer Institut, Universität München, München, ${ }^{4} / I$. Innere Abteilung, Universitätsklinikum Rudolf-Virchow Standort Wedding, Berlin

Key words: EBV; CMV; cytological smears; herpes simplex; HIV; mouth, diseases; oral mucosa.

Angelika Langford, Abteilung für zahnärztliche Chirurgie/Oralchirurgie-Nord, Föhrerstr. 15, D-1 Berlin 65, Deutschland

Accepted for publication July 7, 1991
The oral mucosa is an integral part of the mucocutaneous barrier, which protects against physical, chemical and biologic noxious stimuli (1). Continuous viral, bacterial or mycotic stimulation, modification of the epithelial structure and local or systemic immunologic alterations can lead to disturbances of the mucosal barrier function, resulting in clinical and morphological alterations and dysfunctions of the mucosa (2). During HIV-infection different oral manifestations are found (3). Oral lesions due to herpes viruses are of special clinical relevance, such as the EBV associated hairy leukoplakia $(4,5)$, or CMV induced ulcerations (6), and often show unusual clinical symptoms, localization and/or resistance to therapies.

Since it is often difficult to gain biopsies for diagnosis or for therapy monitoring, it was the purpose of the present study to establish a non-invasive technique for the detection of herpes group viruses.

\section{Material and methods}

39 HIV-seropositive patients and 19 HIV-seronegative controls were includ- ed in this study. HIV seropositivity was stated by ELISA (DuPont) and confirmed by Western blot. Complete histories and examinations of the oral cavity were done initially and reevaluated after 8 months. The clinical status was diagnosed according to the definition of the Centers for Disease Control (CDC) (7). Progression of HIV-associated disease was defined as clinical deterioration of a patient, resulting in the change of CDC-group (7). $\mathrm{CD} 4 / \mathrm{CD} 8$ ratios and absolute numbers of $T$-helper lymphocytes per $\mu \mathrm{l}$ blood were determined according to standard methods (8).

Cytologic smears (CS) were taken from the lateral border of the tongue using a metal spatula. After dissolving in phosphate buffered saline (PBS) and centrifugation (150 g/5 min) trypsine $(0.2 \%)$ was added to the cell solution in order to separate the epithelial cells from adhering detritus and mucus. The cell suspension was repeatedly washed with PBS, centrifugated (100 g/5 min) and was filtered using a teflon filter. Afterwards the superfluous liquid was removed and the quantity of cells was controlled in a Neugebauer counting chamber (optimal density of cells: $80-100$ cells $/ \mu \mathrm{l})$. After adding $10 \mu \mathrm{l}$ acetone the cell suspension was immediately distributed onto poly-L-Lysine coated glass slides, air dried (10 min), fixed with acetone ( $5 \mathrm{~min})$, air dried (10 $\mathrm{min})$ and stored at $-20^{\circ} \mathrm{C}$. After fixation (5 $\mathrm{min}$ ) and air drying (10 min) one slide/ patient was counterstained with hemalaun to control the quality of the cell preparation.

For detection of structural proteins of EBV (nuclear antigen: NA, virus capsid antigen: VCA, early antigen: EA) (dilution: 1:200; Prof. Wolf, München) and CMV (dilution: 1:25; Dakopatts) monoclonal antibodies were applied using the APAAP technique (9). As pretreatment for this procedure slides were defrosted $(30 \mathrm{~min})$, fixed with acetone (10 $\mathrm{min}$ ) and airdried (10 $\mathrm{min})$.

EBV and CMV DNA probes were obtained from Enzo (Ortho Diagnostics). For in situ hybridization (ISH) slides were defrosted ( $30 \mathrm{~min})$, air dried (30 min) and fixed with acetone (10 min). To avoid unspecific reactions with the streptavidin horseradish peroxidase complex resp. due to the presence of endogenous phosphatase slides were 
treated with $0.5 \%$ triton (10 $\mathrm{min}$ ) resp. $\mathrm{H}_{2} \mathrm{O}_{2} /$ methanole (5 min). After washing (aqua dest) and air drying (5 min) the probe reagent was applied and the slides were covered with acid-cleaned cover glasses. Denaturation was performed by placing the slides in a $92 \pm 2{ }^{\circ} \mathrm{C}$ incubator for $4 \mathrm{~min}$ and then immediately placing the slides in a $37^{\circ} \mathrm{C}$ incubator for 20 min to allow for hybridization. Following hybridization, the cover glasses were removed, the slides incubated with the post hybridization solution (1 mM phosphate buffer, $13 \mathrm{mM}$ $\mathrm{NaCl}, 50 \%$ formamide) and repeatedly washed (10 mM PBS/5 mM EDTA). Hybridized biotinylated DNA probes were detected using an avidin-biotinylated horseradish peroxidase system (10) with aminoethylcarbazole as chromogen. Finally the cell preparations were lightly counterstained using Fast Green (4 min) and coverglassed with glycerin jelly.

Using the APAAP technique the specificity of monoclonal antibodies was tested on Raji cells (negative control for EBV) and EBV-infected Raji and P3HR 1 cells (positive controls for EBV), on HEL cells (negative control for CMV) and CMV (strain AD169) infected HEL cells (positive control for CMV). For in situ hybridization the specificity of probes was tested on Ramos and P3HR 1 cells (negative control for EBV) and on Raji cells and EBV (strain B95-8) infected Ramos and P3HR 1 cells (positive control for EBV), on MRC-5 and HEL cells (negative control for CMV) and on CMV infected MRC-5 and HEL cells (positive control for CMV).

To exclude unspecific reactions cytologic slides, not incubated with the primary antibody respectively DNA probe, were included in all other test procedures.

The slides were microscopically evaluated using a Leitz Orthoplan microscope with a primary magnification of $\times 250$. All cells of each slide - in average about 1500 cells - were evaluated. The slides were scored as being either positive or negative. Positive cases with less than five positive cells/slide were classified as "+", those with 5 to 10 positive cells as " $++"$ and those with more than 10 positive cells as " +++ ". Positivity was also designated as nuclear, cytoplasmic or whole cells. Positive cells were characterized as cytomegalic, enlarged or normal sized cells. The mean value and standard error of the mean of the number of positive cells/slide were determined. To decide whether there

Table 1. Ratio of CD4/CD8 positive cells and absolute number of CD4 positive cells/ $\mu$ I (CD4 abs/ $\mu \mathrm{l}$ ) (peripheral blood).

\begin{tabular}{lccccc}
\hline & HIV + & ASY & ARC & AIDS & HL \\
\hline Number of patients & 39 & 6 & 12 & 21 & 19 \\
CD4/CD8 & & & & & \\
Average & 0.3 & 0.7 & 0.4 & 0.1 & 0.3 \\
Standard deviation & 0.04 & 0.1 & 0.5 & 0.02 & 0.06 \\
Median & 0.3 & 0.7 & 0.4 & 0.1 & 0.2 \\
Range & $0.04-1.0$ & $0.3-1.0$ & $0.2-0.8$ & $0.04-0.4$ & $0.04-1$ \\
CD4 abs/ $\mu \mathrm{l}$ & & & & & \\
Average & 195 & 532 & 350 & 96 & 137 \\
Standard deviation & 39.1 & 162 & 72.5 & 17.4 & 28.8 \\
Median & 112 & 467 & 316 & 65 & 99 \\
Range & $7-744$ & $214-744$ & $155-570$ & $7-250$ & $7-340$ \\
\hline
\end{tabular}

HIV + : HIV seropositive patients; ASY: Asymptomatic HIV + patients; ARC: HIV + patients with ARC symptoms; AIDS: HIV + patients with AIDS symptoms; HL: HIV + patients with hairy leukoplakia (HL).

was a significant difference or correlation between the immunocytochemical results gained from patients of different clinical groups a parameter free test (Utest Mann-Whitney) was used. Spearmann's correlation test was applied to determine relations between the immunocytochemical results and the clinical and immunologic data.

\section{Results \\ Clinical results}

Nineteen healthy HIV-control persons (average age: 33 years; men $n=9$, women $n=10$ ) were included in the study. HIV + patients (men: $n=35$, women: $n=4$; average age: $34.9 \mathrm{yr}$ ) were in different risk groups for acquiring HIV-infection: homo- or bisexual males $(28 / 39)$, i.v. drug users $(9 / 39$; men: $n=$
6, women: $n=3$ ), hemophiliac $(1 / 39)$ and heterosexual women (1/39). The patients were in different clinical stages of HIV-infection: 6 patients were asymptomatic, 12 patients showed ARC symptoms (CDCIII/IVA) and 21 patients suffered from AIDS manifestations (CDC IV B-E).

During the observation time of 8 months in 7 patients progression of HIV-associated disease was noted, while 11/21 patients with AIDS manifestations died.

In all HIV + patients the CD4/CD8 ratio was decreased (average: 0.3 ; range: $0.04-1.0$ ), while in $60 \%$ the absolute number of CD4 cells was below $100 / \mu 1$ (average: $195 / \mu \mathrm{l}$; range: $7-744 / \mu \mathrm{l}$ ) (Table 1). All patients with a CD4/CD8 ratio $\geq 0.1$ and/or an absolute number of CD4 cells $\leq 100 / \mu$ l showed clinical

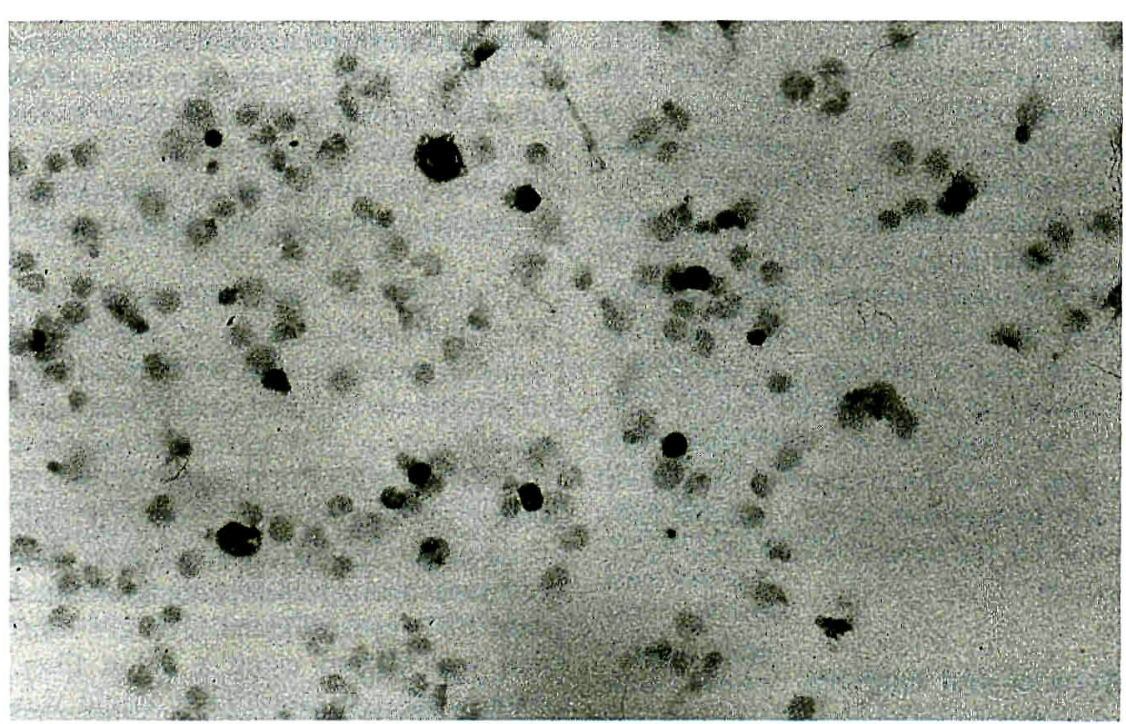

Fig. 1. Positive reactions in EBV infected Raji cells were located within nucleus, occasionally within cytoplasm as well. APAAP $\times 200$. 

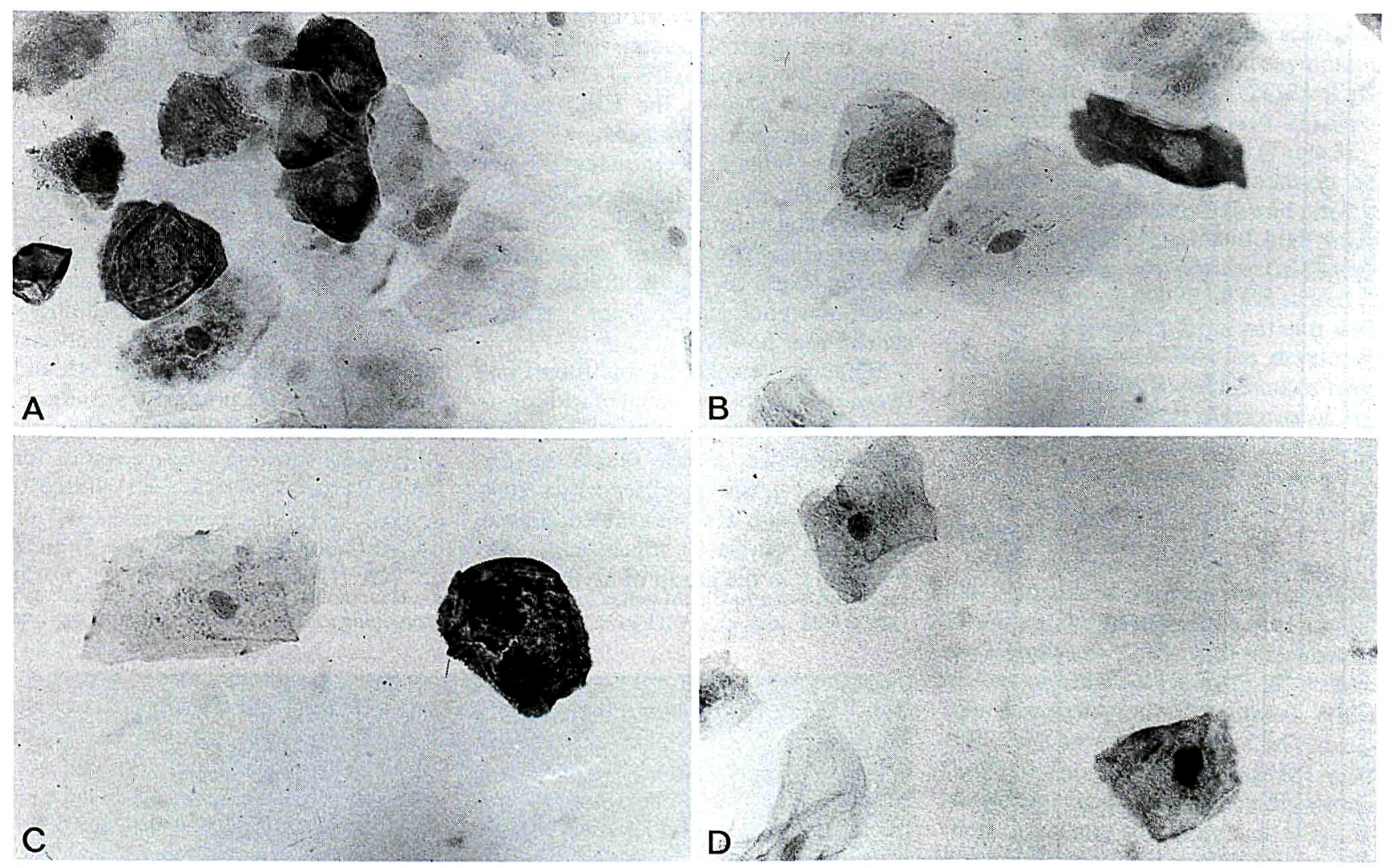

Fig. 2. Positive reactions were found for EBV capsid and/or membrane antigens (A). Flattened (B) or polygonal (C) keratinocytes positive for EBV revealed nuclear (D) and/or cytoplasmatic staining, but in addition cells morphologically not altered also stained positive (CS of HIV + patient, A: APAAP, $\times 300$. B-C: APAAP, $\times 400$.

symptoms of AIDS manifestations. Between the clinical stage of HIV-associated disease and the $\mathrm{CD} 4 / \mathrm{CD} 8$ ratio (Spearmann-test: $P=0.03$ ) as well as the absolute number of CD4 positive cells (Spearmann-test: $P=0.03$ ) significant correlations were found.

Within the oral cavity clinical manifestations of $C$. albicans infection (26/ 39), HSV1/2 associated lesions (5/39), Kaposi's sarcoma $(8 / 39)$ and nonHodgkin's lymphoma (1/39) were observed. In 19 patients (asymptomatic: $n=1$; ARC: $n=7$, AIDS: $n=11$ ) hairy leukoplakia (HL) was clinically diagnosed at the lateral border of the tongue. During the observation time of 8 months three more patients developed this lesion. There was a significant correlation between the clinical finding of HL and the progression of HIV-associated disease (U-test Mann-Whitney: $P=0.015)$. No correlation was found between HL and the clinical stage of HIV-associated disease, serologic immunoparameters (CD4/CD8 ratio, absolute number of CD4 positive cells) or the presence of other oral lesions.

At the time of examination 15 patients received antiviral drugs: AZT
(Retrovir) $n=10$, pentosan polysulfates (HOE/BAY 946) $n=3$, Gancyclovir (DHPG) $n=1$; two patients were under treatment with Acyclovir (Zovirax), starting 2 days before examination. In eight of these patients the clinical symptom of HL was diagnosed; however, antiviral medication showed no effect on the clinical presentation of this lesion.

Table 2. Number of cases positive for EBV nuclear (NA), capsid (VCA) and early antigens (EA) (APAAP) and for EBV DNA (in situ hybridization).

\begin{tabular}{|c|c|c|c|c|c|}
\hline \multirow[b]{3}{*}{$\mathrm{HIV}+$} & \multicolumn{3}{|c|}{ EBV antigen } & \multirow{3}{*}{$\begin{array}{c}\begin{array}{c}\text { EBV antigen } \\
\text { total }\end{array} \\
24 / 39(61 \%)\end{array}$} & \multirow{2}{*}{$\begin{array}{c}\text { EBV DNA } \\
\text { total }\end{array}$} \\
\hline & \multirow{2}{*}{$\frac{\text { NA }}{18 / 39(46 \%)}$} & \multirow{2}{*}{$\frac{\text { VCA }}{13 / 39(33 \%)}$} & \multirow{2}{*}{$\begin{array}{c}\text { EA } \\
3 / 39(8 \%)\end{array}$} & & \\
\hline & & & & & $31 / 39$ \\
\hline $\begin{array}{l}\text { ASY } \\
\text { ARC } \\
\text { AIDS }\end{array}$ & $\begin{array}{ll}2 / 6 & (33 \%) \\
9 / 12 & (75 \%) \\
7 / 12 & (33 \%)\end{array}$ & $\begin{array}{ll}3 / 6 & (50 \%) \\
3 / 12 & (25 \%) \\
7 / 12 & (33 \%)\end{array}$ & $\begin{array}{l}0 / 6 \\
2 / 12 \quad(16 \%) \\
1 / 21 \quad(5 \%)\end{array}$ & $\begin{array}{cc}4 / 6 & (55 \%) \\
9 / 12 & (75 \%) \\
11 / 21 & (52 \%)\end{array}$ & $\begin{array}{cc}4 / 6 & (67 \%) \\
11 / 12 & (92 \%) \\
16 / 21 & (76 \%)\end{array}$ \\
\hline $\begin{array}{l}\mathrm{HL} \\
\text { HL* }\end{array}$ & $\begin{array}{l}13 / 19(68 \%) \\
16 / 22(73 \%)\end{array}$ & $\begin{array}{r}9 / 19(47 \%) \\
11 / 22(50 \%)\end{array}$ & $\begin{array}{l}1 / 19(5 \%) \\
3 / 22(14 \%)\end{array}$ & $\begin{array}{l}16 / 19(84 \%) \\
19 / 22(86 \%)\end{array}$ & $\begin{array}{l}19 / 19(100 \%) \\
22 / 22(100 \%)\end{array}$ \\
\hline $\mathrm{HL}-/ \mathrm{HL}^{*}-$ & $2 / 17(12 \%)$ & $3 / 17(18 \%)$ & $0 / 17$ & $5 / 17(29 \%)$ & $9 / 17 \quad(53 \%)$ \\
\hline${ }_{\text {[Express }}$ & $\begin{array}{l}0 / 19 \\
\text { ion of more th }\end{array}$ & $\begin{array}{l}0 / 19 \\
\text { in one antigen }\end{array}$ & $\begin{array}{l}0 / 19 \\
\text { /patient] }\end{array}$ & $0 / 19$ & $(17 \%)$ \\
\hline
\end{tabular}

HIV + : HIV seropositive (HIV+) patients [ $=39$ ]; ASY: Asymptomatic HIV + patients [n6]; ARC: HIV + patients with ARC symptoms [n=12]; AIDS: HIV + patients with AIDS symptoms $[\mathrm{n}=21]$; HL: HIV + patients with hairy leukoplakia $(\mathrm{HL})[\mathrm{n}=19]$; HIV - : HIV seronegative persons $[=19]$; HL*: HIV + patients with HL or later development of HL $[\mathrm{n}=$ 22]; HL - / HL* - : HIV + patients without HL or later development of HL $[n=17]$. 


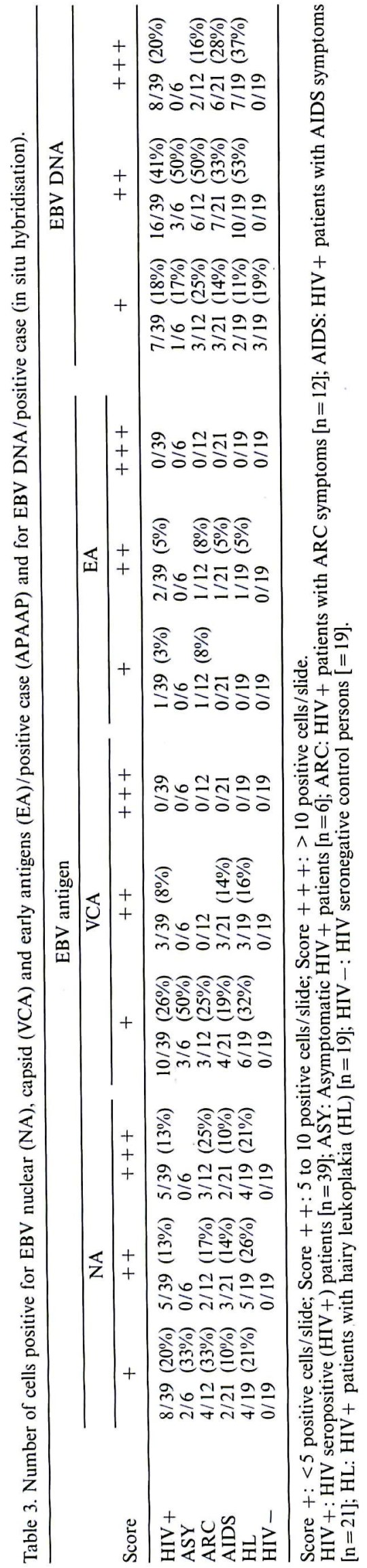

While all cytologic cell preparations (CS) from control persons were EBV negative, 24/39 (61\%) CS of HIV + patients were positive for EBV capsid and/or membrane antigens (APAAP) (Fig. 2A) (Table 2). Keratinocytes positive for EBV showed flattened (Fig. 2B) or polygonal morphology (Fig. 2C) with nuclear (Fig. 2D) and/or cytoplasmic staining (Figs. 2B, C), in addition some cells morphologically not altered stained also positive.

While no correlation was found between the number of patients with positive results and the clinical stage of HIV-associated disease (Table 3), the amount of positive cells/positive case correlated with HIV-associated clinical symptoms (Table 3) (Spearmann-test: $P=0.001)$ : in the group of asymptoma- tic patients all positive cases were scored as "+", while in the group of ARC and AIDS patients most positive cases showed more than 10 positive cells/slide (Table 3). In the group of patients with HL $16 / 19$ patients $(84 \%)$ revealed positive results for EBV-antigens. There were significant correlations between the clinical finding of HL and patients with positive results for EBV antigen (Spearmann-test: $P=0.001$ ). Additionally, correlations were found between the presence or development of $\mathrm{HL}$ and the expression of certain EBV antigens resp. the number of positive cells/case: all patients showing positive results for EA (ARC: $n=2$, AIDS: $n=1$ ) (Table 2) or positive results scored as " ++ " or " +++ " for VCA (AIDS: $n=3$ ) 'and/ or NA (ARC: $n=5$, AIDS: $n=5$ )

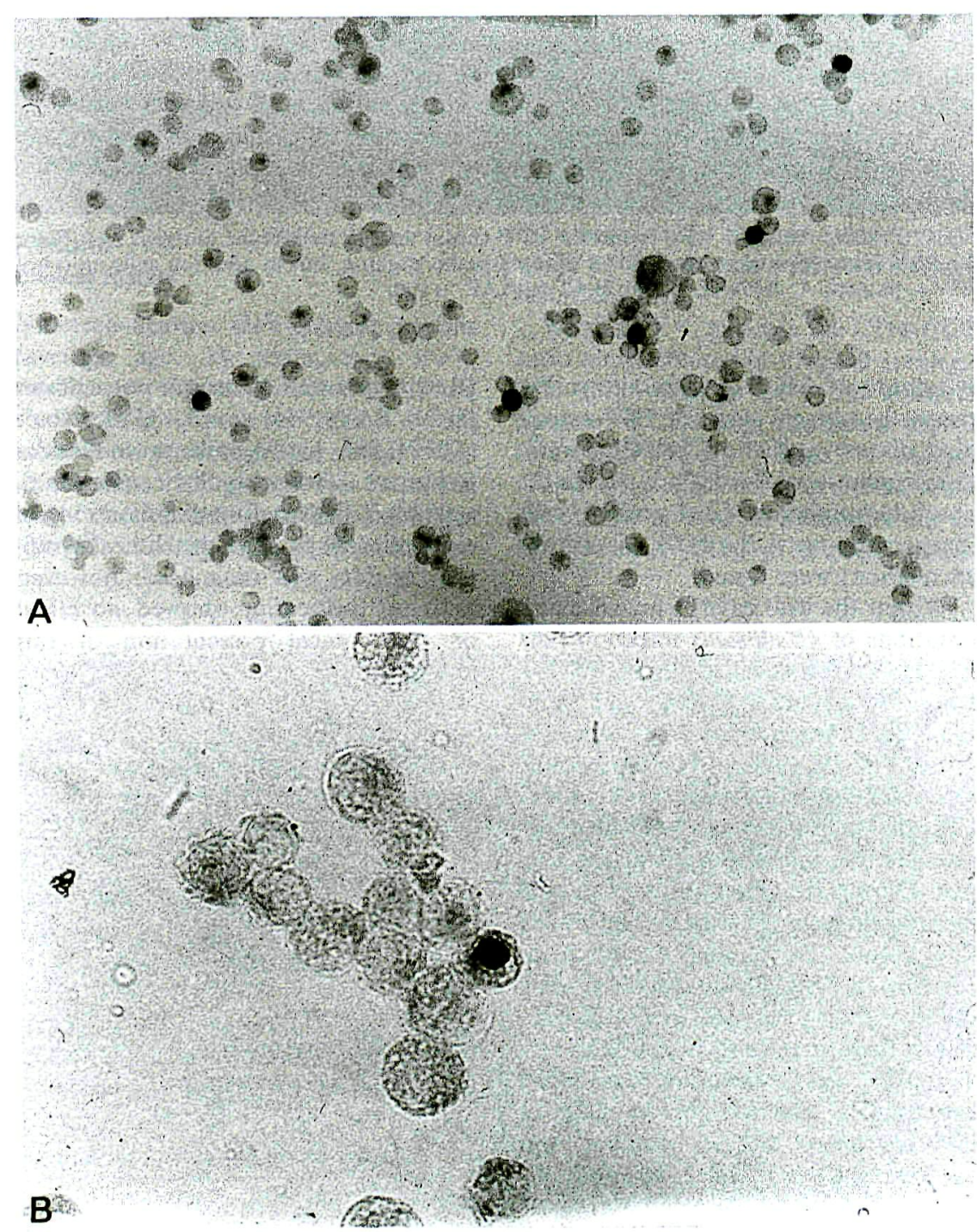

Fig. 3. On Ramos cells and P3HR1 cells positive reactions were not observed, while positive staining was located within the nucleus and in cytoplasm of EBV infected Ramos cells (A) ISH $\times 200$ and of EBV infected P3HR1 cells (B) ISH $\times 400$. 


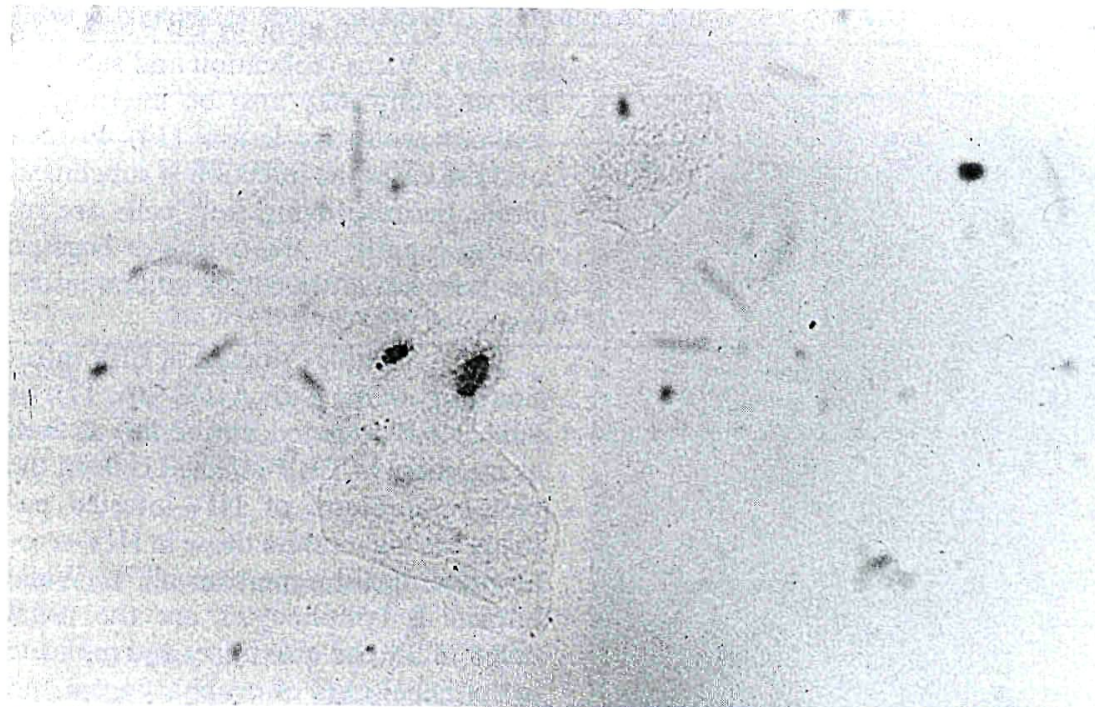

Fig. 4. EBV-DNA was found within nucleus and cytoplasm of cells with intranuclear inclusions and occasionally also in cells morphologically not altered. CS of HIV + patient, ISH $\times 300$. showed the clinical symptom of $\operatorname{HL}(n=$ $16)$ or developed HL during an observation time of 8 months $(n=3)$ (Table 3$)$. Compared with $61 \%$ positive cases $(24 /$ $39)$ in the group of HIV + patients and $86 \%(19 / 22)$ in the group of patients with presence or later development of $\mathrm{HL}$ only five of 17 patients without $\mathrm{HL}$ $(29 \%)$ were EBV antigen positive (Table 2).

$E B V-D N A$ - On Ramos cells and $\mathrm{P} 3 \mathrm{HR} 1$ cells positive reactions were not observed, while positive staining was located within the nucleus and in the cytoplasm of Raji cells, in EBV infected Ramos and P3HR1 cells (Fig. 3A, B).

EBV-DNA was found within the nu-

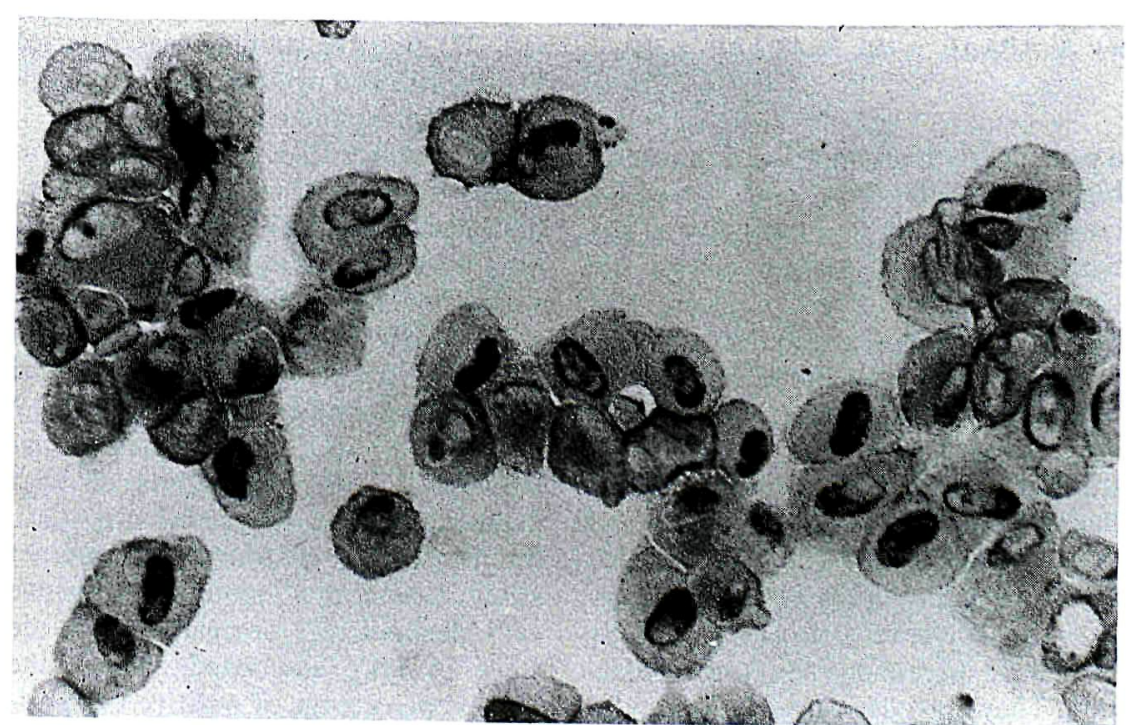

Fig. 5. While HEL cells were negative for CMV structural antigens, CMV infected HEL cells showed positive reactions mainly within nucleus, occasionally within cytoplasm as well. APAAP $\times 350$, without counter staining. cleus and the cytoplasm of cells with intranuclear inclusions and occasionally as well in cells morphologically not altered (Fig. 4). 79\% of CS (31/39) were positive for EBV-DNA compared to $3 /$ 19 HIV seronegative controls (Table 2). While again the number of positive cases in the different clinical stages varied not significantly, a strong correlation was found between the number of positive cells/positive case and the clinical classification of patients. While in positive cases of HIV seronegative controls $(3 / 19)$ less than 5 cells were positive for EBV DNA, in the group of $\mathrm{HIV}+$ patients the number of positive cells/positive CS was mainly scored as
" ++ " or " +++ ". Cases scored as " +++ " were not found in asymptomatic patients, but in $16 \%(2 / 12)$ of patients with ARC and in $28 \%(6 / 21)$ of patients with AIDS symptoms (Table 3).

There was a strong correlation between the occurrence of HL and positive results for EBV-DNA and high numbers of positive cells/positive CS (Spearmann-test: $P=0.0002)$ : all CS scored as " +++ " were taken from patients with HL $(n=7)$ or who later on developed HL $(n=1)$ (Table 3$)$. All CS taken from areas with the clinical diagnosis of $\mathrm{HL}$ $(19 / 19)$ and from clinically uninvolved areas in patients who developed HL $(n=3)$ were positive for EBV-DNA (Table 2).

CMV antigen - Positive staining for CMV structural antigens and for CMV DNA was found within the nucleus and the cytoplasm of cells with intranuclear inclusions and occasionally as well in cells morphologically not altered. While HEL cells were negative for CMV structural antigens, CMV infected HEL cells showed positive reactions mainly within the nucleus and the cytoplasm (Fig. 5). Using the APAAP technique in the group of $\mathrm{HIV}+$ patients 22/39 CS (56\%) were positive for CMV, while $2 /$ 19 controls $(11 \%)$ showed positive results as well (Table 4). Expression of viral structural antigens was observed within keratinocytes revealing enlarged nuclei (Fig. 6A) and perinuclear halo (Fig. 6B), mostly associated with cytoplasmic positive reactions.

While in the group of asymptomatic $\mathrm{HIV}+$ patients and in HIV-seronegative controls less than 5 positive cells/ case were found, positive CS of ARC and AIDS patients were mainly scored as " ++ " or " +++ ". No correlation was found between the presence of $\mathrm{HL}$ and positive results for $\mathrm{CMV}$ antigen (Table 4).

CMVDNA - MRC-5 cells and HEL cells were negative for CMV DNA, while within the nucleus of CMV infected MRC-5 cells (Fig. 7) and HEL cells positive reactions were observed. By means of ISH 27/39 (69\%) of HIV + patients showed positive results for CMV DNA (Fig. 8), while in 4/19 $(21 \%)$ HIV seronegative controls positive results with less than 5 positive cells/CS were found (Table 4). In the different clinical stages the number of patients with positive results for CMV DNA was similar. Compared with asymptomatic $\mathrm{HIV}+$ patients ARC or AIDS patients showed an increased frequency of positive cases scored as 

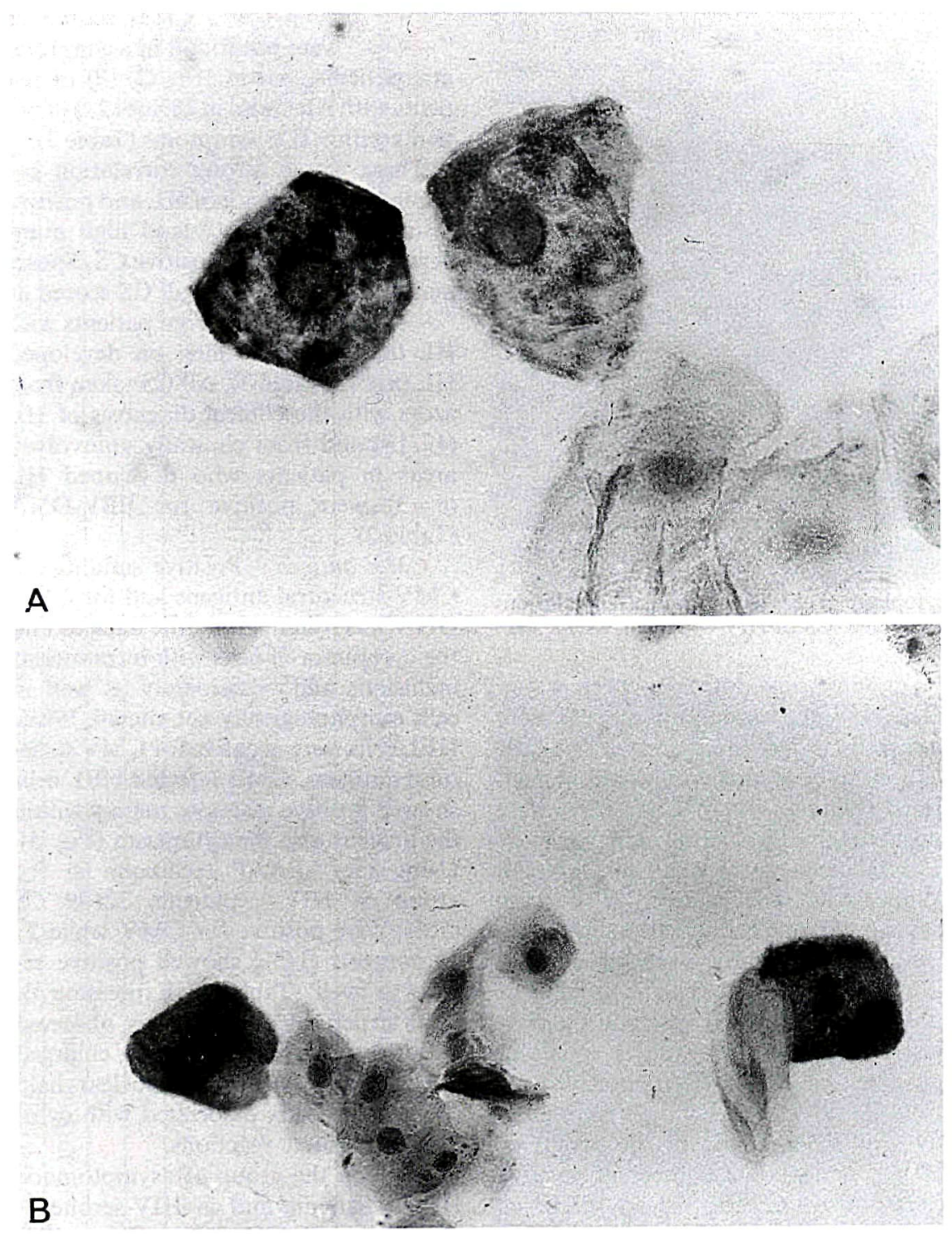

Fig. 6. Positive staining for CMV structural antigens was found within nucleus and/or cytoplasm of keratinocytes revealing as signs of viral infection enlarged nuclei (A) with perinuclear halo (arrow) (B). CS of HIV + patient: A: APAAP, $\times 450$. B: APAAP, $\times 300$.

“+” or " +++ " (Table 4). Positive results for antigens/DNA of both viruses were not correlated with the medication of antiviral drugs ( $n=15$ patients). However, one AIDS patient under medication with Gancyclovir (DGHP) (duration: 4 months prior sampling) was negative for EBV and $\mathrm{CMV}$ in both techniques, while 2 patients receiving Acyclovir (Zovirax) for 2 days before sampling revealed positive results for viral antigens/DNA.

\section{Discussion}

The pathogenesis of AIDS may be influenced by several cofactors $(11,12)$. Herpes viruses may be of special importance, because they are ubiquitous, have ding of CMV in urine or EBV and HSV in saliva. Virus replication and subclinical shedding may also be intermittent without producing lesions (14). In each of these cases the infection is subclinical either because dying host cells are replaced rapidly in the tissues or because the host has little or no inflammatory response (13-15).

There is ample evidence of EBV infection in patients with AIDS $(16,17)$; titers of EBV-related antibodies as well as numbers of EBV-infected cells in the peripheral blood of HIV-infected patients are higher than those in HIV-seronegative healthy persons (17). While human B lymphocytes are the usual target, EBV can also infect and replicate in epithelial cells of oropharyngeal and genital sites (18-21). The receptor for EBV, which corresponds to the complement fraction 3rd receptor (C3), has been identified on B-cells, certain T cells (22) and on keratinocytes of the middle and upper spinous layer of parakeratinized epithelium (23). In HL epithelial cells with this plasma membrane receptor are known as the site of replicating virus (23).

In the present study $61 \%$ (APAAP) resp. $79 \%$ (ISH) of oral CS gained from HIV-infected patients contained keratinocytes positive for EBV. Similar results were gained using electronmicroscopy (negative staining technique), where $53 \%$ of HIV-infected patients showed positive results (unpublished), using in situ hybridization, where EBV expression was found in up to $76 \%$ of homosexual men (24) or by cytospin in situ hybridization technique in $23 / 25$ cases of HL (25). As described in other studies $(12,27)$ positive staining was detected in cells with and without phenotypic evidence of viral infection.

Excretion of EBV has been stated as sensitive marker of underlying immunodeficiency. In HIV-infected patients high levels of EBV excretions correlated with a high probability of HIV-progression, prior to significant changes in CD4/CD8 ratios (24), while Alsip and coworkers found higher levels of EBV excretion in AIDS patients than in patients with ARC symptoms or with acute infectious mononucleosis (27). Similar results were found in the present study, where the amount of positive cells/positive case correlated with the stage of HIV associated disease: the highest percentage of positive CS/positive case was found in the group of patients with ARC and AIDS manifestations, suggesting that these patients 
Table 4. Number of cells positive for CMV antigen/positive case (APAAP) and for CMV DNA/positive case (in situ hybridisation).

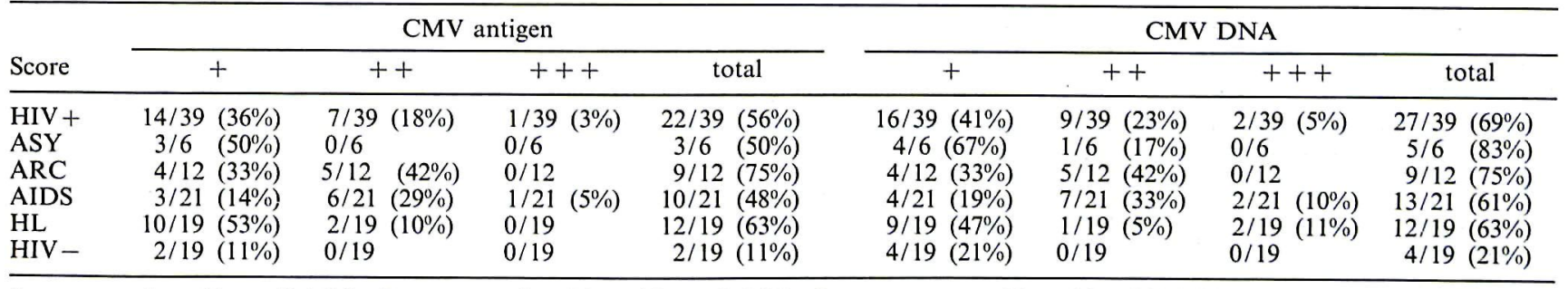

Score $+:<5$ positive cells/slide; Score $++: 5$ to 10 positive cells/slide; Score $+++:<10$ positive cells/slide.

HIV +: HIV seropositive (HIV +) patients [ $\mathrm{n}=39]$; ASY: Asymptomatic HIV + patients [ $\mathrm{n}=6]$; ARC: HIV + patients with ARC symptoms $[n=12]$; AIDS: HIV + patients with AIDS symptoms $[n=21]$; HL: HIV + patients with hairy leukoplakia (HL) [n=19]; HIV $-:$ HIV seronegative control persons $[n=19]$.

have an altered immunoregulation of EBV.

In contrast, positive results in HIVseronegative persons examined in the present study have been a very rare finding and positive cases $(3 / 19)$ revealed a very low number of positive cells. Similar results were described by ALSIP et al. (27) while others found low as well as occasionally high excretion of EBV in the general population $(13,14,16)$. This may occur due to asymptomatic shedding, which has been demonstrated in up to $60 \%$ of healthy adults or due to immunosuppression caused by other factors than HIV-infection (16).

Apart from the clinical stage the positive results for EBV correlated with the clinical diagnosis of $\mathrm{HL}$, and seemed even to preceede the clinical manifestation of HL in three patients: all patients revealing positive results for EA or positive results for VCA or NA with high numbers of positive cells/case showed the presence or later development of
HL. This lesion is a frequent and early clinical symptom pointing to an underlying immunodeficiency. It was first described in HIV infected homosexual men, later as well in all other groups at risk for HIV-infection $(3,4)$. HL has been considered to be a highly predictive lesion for the development of AIDS (28), a fact which has also been stated in the present study. The correlation between the clinical finding or later development of HL with the progression of HIV-associated disease may be reflected in the immunocytochemical results for EBV: while $61 \%$ of HIV + patients and $84 \%$ of HIV + patients with HL showed positive results for EBV, only five of 17 patients without presence or later development of HL were EBV antigen positive. Since the clinical diagnosis of HL may have further consequences for the individual patient, it has been postulated that for confirmation biochemical proof of EBV would be necessary (5). The examination of oral CS, de-

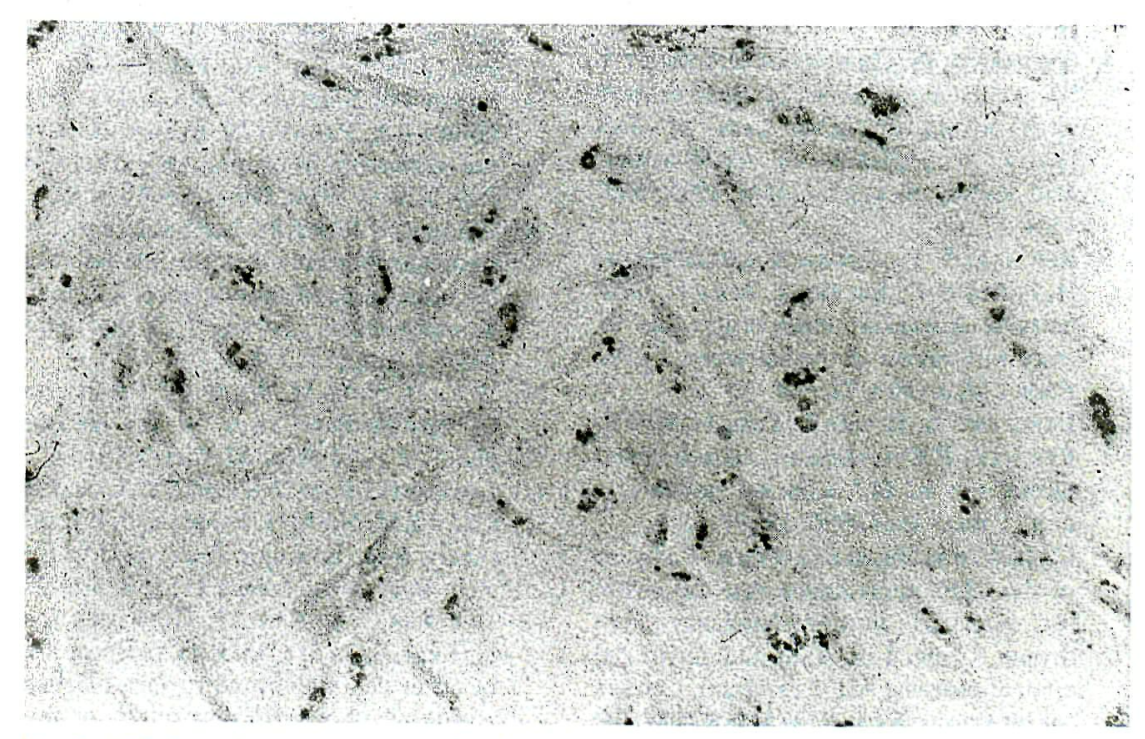

Fig. 7. MRC-5 cells were negative for CMV DNA, while within nucleus of CMV infected MRC-5 cells positive reactions were observed. ISH $\times 200$. scribed in this study, offers the possibility of gaining samples from a relatively large area by means of a non-invasive technique. The diagnostic accuracy is comparable with results gained by biopsies $(4,5)$.

The increased load of EBV found in the oral CS of our patients may have various consequences: since EBV itself is an effective unspecific immunostimulant it may trigger the progression of the disease by activation of $\mathrm{CD}^{+}$epithelial cells and thereby coactivating latent HIV which leads to destruction of these cells $(17,29)$. The decreasing number of CD4 cells may in turn favor further Bcells already latently infected by EBV to complete a full lytic cycle of viral replication without prior immunoelimination. Whether the increased finding of oral lymphomas in HIV-infected patients may be related to the increased EBV expression (30), is yet unknown, but may well relate to similar mechanisms.

CMV can be transmitted via saliva as well as through blood and sexual contact (16). After the initial replication in epithelial cells CMV takes up long-term residence in circulating leukocytes.

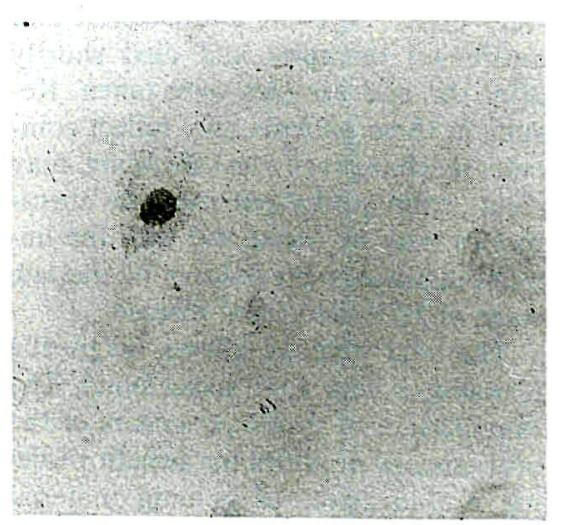

Fig. 8. Mainly intranuclear CMV DNA was detected in $69 \%$ of CS of HIV + patients. CS of $\mathrm{HIV}+$ patient. ISH $\times 300$. 
More than $50 \%$ of healthy adults and almost $100 \%$ of HIV positive homosexuals have serum antibodies to CMV (31). CMV has been isolated from the pharynx in $74 \%$ (32) and from parotid saliva in more than $65 \%$ of patients with AIDS (33). The examination of oral CS in the present study showed comparable results: 56\% (APAAP) resp. 69\% (ISH) of CS from HIV-infected patients showed positive results for CMV antigen resp. CMV DNA, while in control CS $11 \%$ resp. $21 \%$ were positive for CMV antigen resp. CMV DNA. In addition to detection of CMV antigen/ DNA within cytomegalic cells, positive results were found also in the nucleus and cytoplasm of cells without enlargement or inclusion formation. Similar findings have been described by others in various tissues (34-36).

In contrast to their protective function, elevated serum titers of CMV antibodies seem to be a significant predictor for the development of AIDS (31). While symptomatic infection with CMV occurs very rarely in healthy adults, CMV is a critical opportunistic pathogen in the immunocompromised host (31). Whether the enhancement of local CMV replication correlates with increasing levels of CMV viremia during the progression from ARC to AIDS symptoms and CMV involvement of various organs is under investigation.

For both viruses comparatively low numbers of positive results were found in the group of AIDS patients examined in the present study. This may partly be due to CS of four patients with AIDS symptoms, in which antigens/DNA of EBV and CMV were not detected. In one of these patients treatment with DHPG for a period of 4 months before sampling may be the reason for negative results. The remaining three patients received ACT, were under different antibacterial and antifungal therapies and died shortly after the oral samples were taken. Results in these patients may reflect coincidental changes of viral shedding, may result from prolonged multiple therapies or may be connected with the immunoregulatory breakdown of the late stage of HIV-associated disease.

The oral mucosa allows diagnostic procedures with easy accessibility. The examination of cytologic smears of the oral mucosa provides the benefit of being non-invasive, of gaining material from a relatively large surface compared to biopsy, and of repeated sampling of the same patient during clinical follow- up. However, due to the presence of cell detritus, mucus, bacterial and fungal micro-organisms adhering to the epithelial cells the cytospin technique, used in a prestudy, had resulted in an unequal distribution of epithelial cells. Due to a different technique, which was developed to gain cytologic cell preparations with single cell suspension, the examination of single epithelial cells was possible. In further prospective studies it will be evaluated whether serial samplings of oral CS taken from the same patient can facilitate assessments of the effects of antiviral therapies and give insight into the possible role of these viruses in HIV-associated disease.

Acknowledgments - The authors wish to thank Ms. R. Bleskens, G. Kulins, H. OldENBURG and Mr. H. v. SPRECKELSEN for competent laboratory assistance and Mr. J. ECKERT and R. HOEY for excellent photography. In part supported by Bundesministerium für Forschung und Technologie Grant No. II072-88.

\section{References}

1. Bienenstock J, Befus AD. Mucosal immunology. Immunology 1980; 41: 249-70.

2. Hill MW. Cell renewal in oral epithelia. In: Meyer J, Squier CA, Gersón SJ, eds. The structure and function of oral mucosa. Oxford: Pergamon Press, 1984: 53-82.

3. Reichart P, Gelderblom Hir, Becker J, KUNTZ A. AIDS and the oral cavity. The HIV-infection: virology, etiology, origin, immunology, precautions and clinical observations in 110 patients. A review. Int J Oral Maxillofac Surg 1987; 16: 129-53.

4. Greenspan JS, Greenspan D, Lennette ET, et al. Replication of Epstein-Barr virus within epithelial cells of oral "hairy" leukoplakia, an AIDS-associated lesion. $N$ Engl J Med 1985; 313: 1564-71.

5. Reichart P, LangFord A, Gelderblom H, Pohle H-D, Becker J, Wolf H. Oral hairy leukoplakia: observations in 95 cases with review of the literature. $J$ Oral Pathol Med 1989; 18: 410-5.

6. Langford A, Kunze R, Timm H, Ruf B, Reichart P. Cytomegalovirus associated ulcerations in HIV-infected patients. $J$ Oral Pathol Med 1990; 19: 71-6.

7. Centers for Disease Control. Revision of the CDC surveillance case definition for acquired immunodeficiency syndrome. Council of state and territorial epidemiologists; AIDS program, Centers for infectious diseases. $M M W R$ 1987; 36: 1-15 (Suppl.).

8. Davey RT, LANE HC. Laboratory meth- ods in the diagnosis and prognostic staging of infection with human immunodeficiency virus type 1. Rev Inf Dis 1990; 12: $912-30$.

9. Cordell JL, Falini B, Erber WN, et al. Immunoenzymatic labeling of monoclonal antibodies using immune complexes of alkaline phosphatase and monoclonal anti-alkaline phosphatase (APAAP complexes). J Histochem Cytochem 1984; 32: 219-29.

10. Hsu SM, Raine L, Fange N. A comparative study of the peroxidase-antiperoxidase method and an avidin-biotin complex method for studying polypeptide hormones with radioimmunoassay antibodies. Am J Clin Pathol 1981; 75: 734-8.

11. SKolnik PR, Kosloff BR, Hirsch MS. Bidirectional interactions between human immunodeficiency syndrome and cytomegalovirus. J Infect Dis 1988; 157: 508-14.

12. Uccini S, Vitolo D, Monardo F, et al. Interaction of HIV and EBV at lymphoid tissue level: immunohistochemistry and in situ hybridisation. APMIS 1989; 8: 28-32 (Suppl.).

13. Jordan MC, Jordan GW, Stevens JG, Miller G. Latent herpes viruses of humans. Ann Intern Med 1984; 100: 866-80.

14. WiLDLY P. Herpes viruses. Intervirology 1986; 25: 117-40.

15. CoREY L, SPEAR PG. Infections with herpes simplex viruses. $N$ Engl $J$ Med 1986; 314: 686-91.

16. Berry NJ, MacDonald-Burns D, WANNAMETHEe G, et al. Seroepidemiologic studies on the acquisition of antibodies to cytomegalovirus, herpes simplex virus, and human immunodeficiency virus among general hospital patients and those attending a clinic for sexually transmitted diseases. J Med Virol 1988; 24: 385-93.

17. Rinaldo CR, Kingsley LA, Lyter DW, et al. Association of HTLV-III with Epstein-Barr virus infection and abnormalities of T-lymphocytes in homosexual men. J Infect Dis 1986; 154: 556-61.

18. Sixbey JW, Nedrud JG, Raab-Traub N, Hanes RA, Pagano JS. Epstein-Barr virus replication in oropharyngeal cells. $N$ Engl J Med 1984; 310: 1225-30.

19. Wilmes E, Wolf H. Nachweis von Epstein-Barr-Viren in der Tonsilla palatina bei infektiöser Mononukleose. Klinische Konsequenzen. Laryngol Rhinol Otol 1987; 2 (Suppl.): 278-8.

20. Wolf H, Haus M, Wilmes E. Persistence of Epstein-Barr virus in the parotid gland. J Virol 1984; 51: 795-8.

21. Lung ML, Lam WK, So SY, Lam WP, Chan KH, Ng MH. Evidence that respiratory tract is major reservoir for Epstein-Barr virus. Lancet 1985; 2: 889-92.

22. Larcher C, Schulz TF, Hofbauer J, et al. Expression of $\mathrm{C} 3 \mathrm{~d} / \mathrm{EBV}$ receptor and of other cell membrane surface markers is altered upon HIVl infection of myeloid, T, and B cells. $J$ Acq Imm Def Syndr 1990; 3: 103-8. 
23. Corso B, Eversole LR, Hutt-Fletcher L. Hairy leukoplakia: Epstein-Barr virus receptors on oral keratinocyte plasma membranes. Oral Surg Oral Pathol Oral Med 1989; 67: 416-21.

24. Diaz-Mitoma F, Ruiz A, Flowerdew $\mathrm{G}$, et al. High levels of Epstein-Barr virus in oropharynx: a predictor of disease progression in Human Immunodeficiency virus infection. $J$ Med Virol 1990; 31: 69-75.

25. De Souza Y, Freese UK, Greenspan D, Greenspan JS. Diagnosis of EpsteinBarr virus infection in hairy leukoplakia by using nucleic acid hybridisation and non-invasive techniques. $J$ Clin Microbiol 1990; 28: 2775-8.

26. De Souza Y, Greenspan D, Felton JR, Hartzog JR, Hammer M, GreEnspan JS. Localisation of Epstein-Barr virus DNA in the epithelial cells of oral hairy leukoplakia. $N$ Engl J Med 1989; 320: 1559-60.

27. Alsip GR, Ench Y, Sumaya CV, BosWELL RN. Increased Epstein-Barr virus DNA in oropharyngeal secretions from patients with AIDS, AIDS related complex or asymptomatic human immunodeficiency infections. J Infect Dis 1988; 157: 1072-6.

28. Greenspan D, Greenspan JS, Hearst NG, et al. Relation of oral hairy leukoplakia to infection with the Human Immunodeficiency virus and the risk of developing AIDS. $J$ Infect Dis 1987; 155: 475-81.

29. Birx DL, Redfield RR, Tosato G. Defective regulation of Epstein-Barr virus infection in patients with acquired immunodeficiency syndrome (AIDS) or AIDS-related disorders. $N$ Engl $J$ Med 1986; 14: 874-9.

30. Langford A, Dienemann D, Schürman $\mathrm{D}$, et al. Oral manifestations of AIDSassociated Non-Hodgkin's lymphoma. Int J Oral Maxillofac Surg 1991; 20: 136-41.

31. Drew WL. Cytomegalovirus infection in patients with AIDS. $J$ Infect Dis 1988; 158: 449-56.

32. Quinan GV, Masur H, Rook AH. Herpes virus infections in the acquired im- munodeficiency syndrome. JAMA 1984; 252: 72-7.

33. Marder MZ, Barr CE, Mandel ID. Cytomegalovirus presence and salivary composition in acquired immunodeficiency syndrome. Oral Surg Oral Med Oral Pathol 1985; 60: 372-6.

34. Roberts WH, Hammond S, SNEddon JM, Thesing J, Caldwell JH, ClauSEN KP. In situ DNA hybridisation for cytomegalovirus in colonoscopic biopsies. Arch Pathol Lab Med 1988; 112: 1106-9.

35. Clayton F, Klein EB, Kotler DP. Correlation of in situ hybridisation with histology and viral culture in patients with acquired immunodeficiency syndrome with cytomegalovirus colitis. Arch Pathol Lab Med 1989; 113: 1124-6.

36. Gleaves CA, Myerson D, Bowden RA, Hackman RC, Meyers JD. Direct detection of cytomegalovirus from bronchoalveolar lavage samples by using a rapid in situ DNA hybridization assay. $J$ Clin Microbiol 1989; 27: 2429-32. 
This document is a scanned copy of a printed document. No warranty is given about the accuracy of the copy. Users should refer to the original published version of the material. 